\title{
Subjective and Objective Treatment Needs Assessment in Patients Attending, M.N DAV Dental College and Hospital Solan, Himachal Pradesh
}

\author{
Poonam Mahajan ${ }^{1 *}$, Ajay Mahajan², Rambika Thakur ${ }^{1}$ \\ ${ }^{1}$ Department of Public Health Dentistry, M.N DAV Dental College and Hospital Solan, Himachal Pradesh, India-171001 \\ ${ }^{2}$ Department of Periodontology, Himachal Pradesh Government Dental College and Hospital, Shimla, Himachal Pradesh, India-171001
}

*Correspondence to: Poonam Mahajan, Department of Public Health Dentistry, M.N DAV Dental College and Hospital Solan, Himachal Pradesh, India-171001; E-mail: poonammahajan81@gmail.com

Received date: February 7, 2021; Accepted date: February 18, 2021; Published date: February 25, 2021

Citation: Mahajan P, Mahajan A, Thakur R (2021) Subjective and Objective Treatment Need Assessment in Patients Attending, M.N DAV Dental College and Hospital Solan, Himachal Pradesh. Advanc Dentistry 2(1): pp. 1-7.

Copyright: (C2021 Mahajan P. This is an open-access article distributed under the terms of the Creative Commons Attribution License, which permits unrestricted use, distribution, and reproduction in any medium, provided the original author and source are credited.

\section{ABSTRACT}

Objective: This study is planned on a smaller scale to compare the felt need and normative need among subjects attending Dental Hospital Solan. This an effort to provide essential oral health care to the people of Solan on a superior scale in the future, based on accumulated data, which will facilitate the essential shift from the predominately normative assessment of the need to the incorporation of professionally defined into patientdefined need.

Method: Subjective data was obtained by interview method, while the objective need was assessed by a dental professional on a structured format with predefined indices from randomly selected patients from OPD of DAV Dental College and Hospital Solan.

Results: The majority of patients were from urban areas, graduate, female, and in the age group of 24-35 years. The most common subjective need was found filling and RC (30.7\%). The most common objective need was scaling (36.2\%). Maximum agreement between subjective and objective need was found in subjects from the urban area, educated, females, and in case of chief complaint of decayed teeth (44.7\%) and the discrepancy was found maximum in case of chief $s$ of periodontal problem and uneducated people from the rural area.

Conclusion: This present study indicates low awareness among the population there was a large discrepancy between subjective and objective treatment needs. The utilization of dental services should therefore be improved not only by providing better dental facilities but to a greater extent by increasing people's awareness and knowledge of their own dental disorders.

\section{Keywords:}

Subjective, Objective, Treatment need, Solan

\section{Introduction}

Defining and determining need is easier said than done. 'It is important to recognize the different perspectives illuminating the relationship between the concepts of need, and healthcare needs. Davis proposed a relatively simple definition of need as a subjective feeling state that initiates the process of choosing among medical resources [1].

The measure of need should include the impact of ill health individuals, the degree of dysfunction and the perceptions and attitude of the patients [2]. Although there is no generally agreed definition of need, Bradshaw has described a "taxonomy of needs" which is very helpful in clarifying the concepts.

- Normative Need: Normative need tends to be professionally defined and has a knowledge base or it is a condition which an expert or professional person defined as requiring some action.

- Felt Need: Felt Need is equated with what people want.

- Expressed Need: Demand is felt need turned into action.
- Comparative Need: Comparative Need is measured by reference to a user already receiving the service in question. He recently argued that his taxonomy of need was constrained because of inherent problems with the concept of need [3].

The need for treatment can be conceptualized as two components; namely subjective need and objective need. The subjective need is usually expressed by an individual as the perceived need for treatment and varies from individual to individual according to the psychological social and historical context in which the individual lives. The minor ailment can be preceded as subjective need by the individual in one community and may therefore be transformed in to use of health services where similar ailments in other communities are not. So-called objective need, usually by a professional, is also essential, for example, subjective symptoms may be absent in the early stages of the disease and may remain undetected if a person is not examined by a health professional [4]. Several authors have been reported discrepancies between treatment needs to be perceived by the patients and those assessed by dental professionals $[5,8]$. 
A realistic assessment of treatment needs requires information not only about normative (professional) but also about perceived (lay defined) needs [9]. It can be a useful tool in planning and monitoring health services and health promotion interventions.

Oral health services are appeared to be designed to meet the need of the provider rather than those of the public [10] The paucity of information about the treatment needs and demands of the populations may be a possible reason.

In the particular, a study is planned on a smaller scale to compare the felt need [subjective need of dental services] and normative need [professional need of treatment] among subjects attending DAV Dental College Hospital Solan. Data from this study may reflect to some extent the general situation regarding the needs and demands of dental care of patients visiting DAV Dental College and Hospital Solan. This study is an effort to provide essential oral health care to the people of Solan on a superior scale in the future, based on accumulated data, which will facilitate the essential shift from the predominately normative assessment of the need to the incorporation of professionally defined into patient-defined need. It will encourage a shift in emphasis away from the purely mechanical to the behavioral aspects of treatment. Secondly, it will support the development of a health-oriented model of care in preference to the model that dominates current health services.

\section{Materials and Methods}

Before conducting the study a pilot survey was done to see the feasibility of the study. For the main study, a minimum of 10 subjects were planned for the examination per day for about 5-6 months. 1000 subjects were examined, who was considered as study sample Necessary approval was obtained from the concerned college authority. Informed consent was obtained from the patients.

Patients attend dental hospitals related to various problems, study subjects were selected randomly. Once the subjects were selected, general information of the subjects and "subjective" dental treatment need was collected by interview method.

Then objective dental treatment need was assessed by clinical examination.

All the instruments were sterilized by autoclaving. General information including name, age, sex, educational level, occupation, and location of residence of the subjects and also the reason to visit the dental hospital was recorded using Performa. They were asked about the treatment need,

Table 1: Distribution of subjects according to chief complaint and age. which they were expecting related to the chief complaint. This is considered a subjective treatment need. Once the interview was over, the dentist examined these subjects under illuminated light in a dental chair under aseptic condition. The study subjects were examined not only depending on their chief complaint, but also for other conditions requiring treatment, which was considered as 'objective treatment' need. The examination for dental caries was done with a mouth mirror and CPI probe and treatment need was assessed by Dentition status and treatment need an index. Periodontal status was assessed by using the community periodontal index of treatment needs [2].

The malocclusion status and treatment needs were assessed using Dental Aesthetic Index (DAI) criteria. Prosthetic need Recording was made for each jaw on the objective need for prosthetics. The prosthesis is indicated when there is a missing tooth that requires replacement. The prosthesis is not indicated when a tooth has been extracted for esthetic reasons when they are extracted for orthodontic reasons when the missing teeth are in the posterior most region off the jaw, which does not facilitate the placement of an artificial denture. Objective assessment was done by a single examiner only. Statistical analysis was done by statistical software spss package (version 13). $95 \%$ confidence interval was taken P-value $<0.005$ was considered significant.

\section{Results}

In this particular study total of 1000 patients were examined. The majority of the patients (31.2\%) were in the age group 2534 followed by $15-24$ yrs. The mean age o the sample was 34 years. In the examined sample 416 were males and 584 were females. The population was divided in two main groups urban and rural, 440 in rural area 560 in urban area. Graduate subjects formed a large proportion i.e. $48.9 \%$ (489) While illiterate people constitute only $10.3 \%$ of the sample. There were 251 postgraduates and 157 subjects were with basic qualifications. A very small \% of the subjects attended dental hospital with complaints like bad breath, broken dentures, food lodgement, ulcer, puss, etc. Hence a separate group of other dental problems was created to accommodate the subjects with the above-said complaints which together constitutes $30 \%$ of the complaints.

The distribution of the subjects according to age and chief complaint. Among the subjects who came for regular check-up maximum subjects were in the age group of 15-24 years and in the older age group $68 \%$ had chief complaints of missing teeth (Table 1).

\begin{tabular}{|c|c|c|c|c|c|c|c|c|c|}
\hline \multirow[t]{2}{*}{ Age } & \multicolumn{8}{|c|}{ Chief complaint } & \multirow[t]{2}{*}{ Total } \\
\hline & $\begin{array}{l}\text { Regular } \\
\text { check-up }\end{array}$ & $\begin{array}{c}\text { Decayed } \\
\text { teeth }\end{array}$ & $\begin{array}{l}\text { Bleeding } \\
\text { gums }\end{array}$ & $\begin{array}{c}\text { Staining } \\
\text { or } \\
\text { discoloration }\end{array}$ & Pain & $\begin{array}{l}\text { Irregular } \\
\text { teeth }\end{array}$ & $\begin{array}{l}\text { Missing } \\
\text { teeth }\end{array}$ & Others & \\
\hline $\begin{array}{l}15-24 \\
\text { years }\end{array}$ & $\begin{array}{c}24 \\
(10.16 \%)\end{array}$ & $\begin{array}{c}52 \\
(22.03 \%)\end{array}$ & $\begin{array}{c}14 \\
(5.93 \%)\end{array}$ & $\begin{array}{c}42 \\
(17.7 \%)\end{array}$ & $\begin{array}{c}36 \\
(15.25 \%)\end{array}$ & $\begin{array}{c}62 \\
(26.27 \%)\end{array}$ & $\begin{array}{c}4 \\
(1.69 \%)\end{array}$ & $\begin{array}{c}2 \\
(0.84 \%)\end{array}$ & 236 \\
\hline $\begin{array}{l}25-34 \\
\text { years }\end{array}$ & $\begin{array}{c}6 \\
(1.92 \%)\end{array}$ & $\begin{array}{c}168 \\
(53.8 \%)\end{array}$ & $\begin{array}{c}30 \\
(9.6 \%)\end{array}$ & $\begin{array}{c}16 \\
(5.12 \%)\end{array}$ & $\begin{array}{c}56 \\
(17.94 \%)\end{array}$ & $\begin{array}{c}20 \\
(6.41 \%)\end{array}$ & $\begin{array}{c}6 \\
(1.92 \%)\end{array}$ & $\begin{array}{c}10 \\
(3.20 \%)\end{array}$ & 312 \\
\hline
\end{tabular}




\begin{tabular}{|c|c|c|c|c|c|c|c|c|c|}
\hline $\begin{array}{l}\text { 35-44 } \\
\text { years }\end{array}$ & $\begin{array}{c}13 \\
(6.19 \%)\end{array}$ & $\begin{array}{c}99 \\
(47.14 \%)\end{array}$ & $\begin{array}{c}4 \\
(1.90 \%)\end{array}$ & $\begin{array}{c}42 \\
(20 \%)\end{array}$ & $\begin{array}{c}30 \\
(14,28 \%)\end{array}$ & $\begin{array}{c}2 \\
(0.95 \%)\end{array}$ & $\begin{array}{c}20 \\
(9.52 \%)\end{array}$ & $\begin{array}{c}0 \\
(0 \%)\end{array}$ & 210 \\
\hline $\begin{array}{l}45-54 \\
\text { years }\end{array}$ & $\begin{array}{c}3 \\
(2.4 \%) \\
\end{array}$ & $\begin{array}{c}41 \\
(32.8 \%) \\
\end{array}$ & $\begin{array}{c}0 \\
(0 \%) \\
\end{array}$ & $\begin{array}{c}6 \\
(4.8 \%) \\
\end{array}$ & $\begin{array}{c}35 \\
(28 \%) \\
\end{array}$ & $\begin{array}{c}0 \\
(0 \%) \\
\end{array}$ & $\begin{array}{c}36 \\
(28.8 \%) \\
\end{array}$ & (43.2\%) & 125 \\
\hline $\begin{array}{l}55-64 \\
\text { years }\end{array}$ & $\begin{array}{c}0 \\
(0 \%)\end{array}$ & $\begin{array}{c}10 \\
(13.6 \%)\end{array}$ & $\begin{array}{c}2 \\
(2.73 \%)\end{array}$ & $\begin{array}{c}4 \\
(5.47 \%)\end{array}$ & $\begin{array}{c}4 \\
(5.47 \%)\end{array}$ & $\begin{array}{c}0 \\
(0 \%)\end{array}$ & $\begin{array}{c}45 \\
(61.6 \%)\end{array}$ & $\begin{array}{c}8 \\
(10.9 \%)\end{array}$ & 73 \\
\hline $\begin{array}{c}>65 \\
\text { years }\end{array}$ & $\begin{array}{c}1 \\
(2.27) \%\end{array}$ & $\begin{array}{c}3 \\
(6.81 \%)\end{array}$ & $\begin{array}{c}0 \\
(0 \%)\end{array}$ & $\begin{array}{c}2 \\
(4.54 \%)\end{array}$ & $\begin{array}{r}2 \\
(4.54 \%)\end{array}$ & $\begin{array}{c}0 \\
(0 \%)\end{array}$ & $\begin{array}{c}30 \\
(68.18 \%)\end{array}$ & $\begin{array}{c}6 \\
(13.6 \%)\end{array}$ & 44 \\
\hline Total & 47 & 373 & 50 & 112 & 163 & 84 & 141 & 30 & 1000 \\
\hline
\end{tabular}

Subjective treatment needs of large no of subjects 307 subjects were found to be Filling or RCT,.22.8\% patients did not know about the treatment options. When objective data was assessed by a dental professional, it was found $22.5 \%$ required restoration or RCT and $2 \%$ required no treatment (Table 2 ).

Table 2: Distribution of the patients according to the subjective treatment need.

\begin{tabular}{|c|c|c|c|}
\hline Subjective treatment need & No. of patients (\%) & Objective treatment need & No. of patients (\%) \\
\hline Filling/RCT & $307(30.7 \%)$ & No treatment & $20(2.0 \%)$ \\
\hline Extraction & $87(8.7 \%)$ & Filling/RCT & $186(18.6 \%)$ \\
\hline $\begin{array}{c}\text { Scaling and other periodontal } \\
\text { treatment }\end{array}$ & $126(12.6 \%)$ & Extraction & $362(36.2 \%)$ \\
\hline $\begin{array}{c}\text { Correction of teeth } \\
\text { Replacement of teeth }\end{array}$ & $94(9.4 \%)$ & $\begin{array}{c}\text { Scaling or other periodontal } \\
\text { treatment }\end{array}$ & $88(8.8 \%)$ \\
\hline Don't know & $158(15.8 \%)$ & Correction of teeth & $119(11.9 \%)$ \\
\hline Total & $228(22.8 \%)$ & Total & $1000(100 \%)$ \\
\hline
\end{tabular}

In the case of males, more number of subjects $35.3 \%$ wanted filling and $24.3 \%$ didn't know about the treatment. In the case of females, more subjects wanted scaling, and $21 \%$ didn't know about the treatment options (Table 3).

Table 3: Distribution of the subjects according to sex and subjective treatment need.

\begin{tabular}{|c|c|c|c|c|c|c|c|}
\hline \multicolumn{8}{|c|}{ Subjective Treatment need } \\
\hline Sex & Filling/RCT & Extraction & Scaling & $\begin{array}{l}\text { Correction of } \\
\text { teeth }\end{array}$ & Replacements & Don't know & Total \\
\hline Male & $\begin{array}{c}147 \\
(35.3 \%)\end{array}$ & $\begin{array}{c}32 \\
(7.9 \%) \\
\end{array}$ & $\begin{array}{c}33 \\
(7.93 \%) \\
\end{array}$ & $\begin{array}{c}34 \\
(8.17 \%) \\
\end{array}$ & $\begin{array}{c}70 \\
(16.82 \%) \\
\end{array}$ & $\begin{array}{c}100 \\
(24.03 \%)\end{array}$ & 416 \\
\hline Female & $\begin{array}{c}110 \\
(18.8 \%)\end{array}$ & $\begin{array}{c}51 \\
(8.7 \%)\end{array}$ & $\begin{array}{c}151 \\
(25.85 \%)\end{array}$ & $\begin{array}{c}60 \\
10.47 \%\end{array}$ & $\begin{array}{c}87 \\
(14.89 \%)\end{array}$ & $\begin{array}{c}127 \\
(21.74 \%)\end{array}$ & 584 \\
\hline Total & 317 & 83 & 124 & 92 & 157 & 227 & 1000 \\
\hline
\end{tabular}

A large proportion of the subjects from the rural area were not aware of the treatment options. The major subjective need was filling and replacement $(22.27 \%, 21.9 \%$ respectively). In the case of urban subjects major subjective need filing or RCT. Very few subjects (4.1\%) wanted extraction in the case of urban subjects (Table 4).

Table 4: Distribution of the subjects according to subjective treatment need and location.

\begin{tabular}{|c|c|c|c|c|c|c|c|}
\hline & \multicolumn{7}{|c|}{ Subjective } \\
\hline & Filling/RCT & Extraction & Scaling & $\begin{array}{c}\text { Correction of } \\
\text { teeth }\end{array}$ & Replacements & Don't know & Total \\
\hline Rural & $\begin{array}{c}98 \\
22.27 \%\end{array}$ & $\begin{array}{c}60 \\
13.63 \%\end{array}$ & $\begin{array}{c}40 \\
9.09 \%\end{array}$ & $\begin{array}{c}12 \\
2.72 \% \\
\end{array}$ & $\begin{array}{c}92 \\
21.90 \%\end{array}$ & $\begin{array}{c}138 \\
31.36 \%\end{array}$ & 440 \\
\hline Urban & $\begin{array}{c}219 \\
39.10 \%\end{array}$ & $\begin{array}{c}23 \\
4.10 \%\end{array}$ & $\begin{array}{c}84 \\
15 \%\end{array}$ & $\begin{array}{c}80 \\
14.28 \%\end{array}$ & $\begin{array}{c}65 \\
11.60 \%\end{array}$ & $\begin{array}{c}89 \\
15.89 \%\end{array}$ & 560 \\
\hline Total & 317 & 83 & 124 & 92 & 157 & 227 & 1000 \\
\hline
\end{tabular}


When data was compared in for subjective and objective treatment needs in various age groups, in the age group of 25-34 years $29.9 \%$ of the subjects had similar subjective and objective treatment needs. In the older age group ( $>65$ years) only $5.8 \%$ of the subjects have similar subjective and objective treatment need (Table 5). When data was compared for subjective and objective treatment needs in males and females. More number of Female subjects (58.6\%) had similar subjective and objective treatment needs (Figure 1).

Table 5: Distribution of matched and non-matched treatment needs according to age group.

\begin{tabular}{|c|c|c|c|c|}
\hline \multirow[t]{2}{*}{ Age } & \multicolumn{4}{|c|}{ Treatment need } \\
\hline & matched & non matched & don't know & Total \\
\hline $15-24$ years & $\begin{array}{c}104 \\
23.35 \%\end{array}$ & $\begin{array}{c}64 \\
19.39 \%\end{array}$ & $\begin{array}{c}68 \\
30.22 \%\end{array}$ & 236 \\
\hline $25-34$ years & $\begin{array}{c}132 \\
29.96 \%\end{array}$ & $\begin{array}{c}130 \\
39.3 \%\end{array}$ & $\begin{array}{c}50 \\
22.22 \%\end{array}$ & 312 \\
\hline $35-44$ years & $\begin{array}{c}92 \\
20.67 \%\end{array}$ & $\begin{array}{c}68 \\
20.6 \%\end{array}$ & $\begin{array}{c}50 \\
22.22 \%\end{array}$ & 210 \\
\hline $45-54$ years & $\begin{array}{c}50 \\
11.23 \%\end{array}$ & $\begin{array}{c}38 \\
11.51 \%\end{array}$ & $\begin{array}{c}37 \\
16.44 \%\end{array}$ & 125 \\
\hline $55-64$ years & $\begin{array}{c}41 \\
9.21 \%\end{array}$ & $\begin{array}{c}20 \\
6.06 \%\end{array}$ & $\begin{array}{c}12 \\
5.33 \%\end{array}$ & 73 \\
\hline$>65$ years & $\begin{array}{c}26 \\
5.84 \%\end{array}$ & $\begin{array}{c}10 \\
3.03 \%\end{array}$ & $\begin{array}{c}8 \\
3.5 \%\end{array}$ & 44 \\
\hline Total & 445 & 330 & 225 & 1000 \\
\hline
\end{tabular}

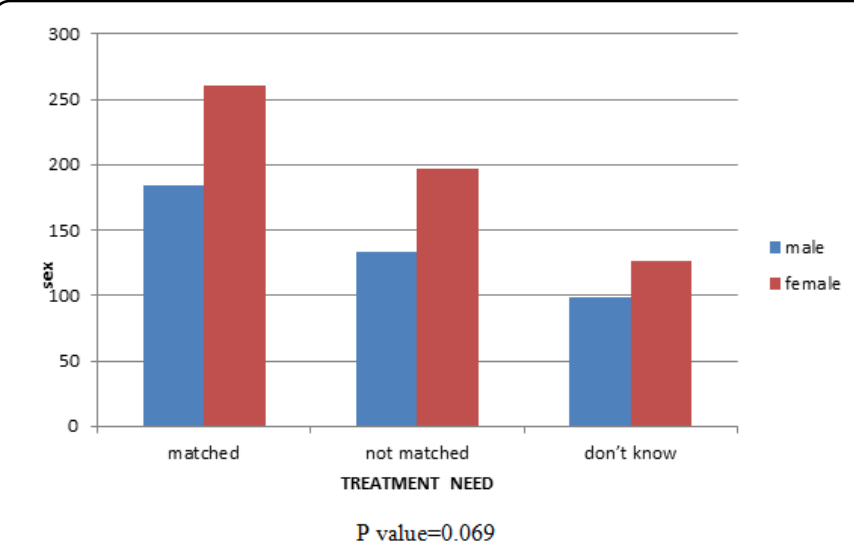

Figure 1: Distribution of subjects according to sex and matched and not matched treatment need.
Subjective and objective needs were compared of rural and urban groups, and it was found that $69.8 \%$ of subjects of the urban sample had similar subjective and objective treatment needs while in the rural population only $30.11 \%$ of subjects had similar subjective and objective needs. The discrepancy was found in $57.5 \%$ of subjects while in the case of the rural population (Figure 1).

The maximum no of subjects $(49.2 \%)$ who had similar subjective and objective treatment need were graduate (Table 6). When data was matched and non-matched subjective and objective treatment needs according to the chief complaint, the maximum no of subjects $(44.7 \%)$ reported to have decayed teeth and aware of the treatment option (Table 7).

Table 6: Distribution of matched and non-matched treatment needs according to education.

\begin{tabular}{|c|c|c|c|c|}
\hline \multirow{2}{*}{ Education. } & \multicolumn{5}{|c|}{ Treatment need } \\
\cline { 2 - 5 } & matched & not matched & don't know & Total \\
\hline illiterate & 34 & 48 & 21 & 103 \\
& $7.64 \%$ & $14.54 \%$ & $9.33 \%$ & 31 \\
\hline basic qualification & 62 & 64 & $13.77 \%$ & 114 \\
& $13.93 \%$ & $19.39 \%$ & $50.66 \%$ & 489 \\
\hline graduate & 219 & 156 & 59 & 251 \\
\hline post graduate & $49.21 \%$ & $47.27 \%$ & $26.22 \%$ & 225 \\
\hline Total & 130 & $18.78 \%$ & 330 & \\
\hline
\end{tabular}


Citation: Mahajan P, Mahajan A, Thakur R (2021) Subjective and Objective Treatment Need Assessment in Patients Attending, M.N DAV Dental College and Hospital Solan, Himachal Pradesh. Advanc Dentistry 2(1): pp. 1-7.

Table 7: Comparison of matched and non-matched treatment needs according to chief complaint.

\begin{tabular}{|c|c|c|c|c|}
\hline \multirow[t]{2}{*}{ Chief complaint } & \multicolumn{4}{|c|}{ Treatment need } \\
\hline & Matched & Not matched & Don't know & Total \\
\hline Regular check up & $\begin{array}{c}25 \\
(5.61 \%)\end{array}$ & $\begin{array}{c}17 \\
5.15 \%\end{array}$ & $\begin{array}{c}5 \\
22.2 \% \\
\end{array}$ & 47 \\
\hline Decayed teeth & $\begin{array}{c}199 \\
(44.7 \%)\end{array}$ & $\begin{array}{c}145 \\
43.9 \%\end{array}$ & $\begin{array}{c}29 \\
12.8 \%\end{array}$ & 373 \\
\hline Bleeding gums & $\begin{array}{c}20 \\
(4.49 \%)\end{array}$ & $\begin{array}{c}20 \\
6.06 \%\end{array}$ & $\begin{array}{c}10 \\
4.4 \%\end{array}$ & 50 \\
\hline $\begin{array}{c}\text { Stains and Discolor- } \\
\text { ation }\end{array}$ & $\begin{array}{c}14 \\
3.14 \% \\
\end{array}$ & $\begin{array}{c}26 \\
7,8 \%\end{array}$ & $\begin{array}{c}72 \\
32 \%\end{array}$ & 112 \\
\hline Pain & $\begin{array}{c}30 \\
6.74 \%\end{array}$ & $\begin{array}{c}30 \\
9.09 \%\end{array}$ & $\begin{array}{c}103 \\
45.7 \%\end{array}$ & 163 \\
\hline Irregular teeth & $\begin{array}{c}44 \\
9.8 \%\end{array}$ & $\begin{array}{c}40 \\
12.12 \%\end{array}$ & $\begin{array}{c}0 \\
0 \%\end{array}$ & 84 \\
\hline Missing teeth & $\begin{array}{c}93 \\
20.8 \%\end{array}$ & $\begin{array}{c}42 \\
12.72 \%\end{array}$ & $\begin{array}{c}6 \\
2.6 \%\end{array}$ & 141 \\
\hline Others & $\begin{array}{c}20 \\
4.49 \%\end{array}$ & $\begin{array}{c}10 \\
3.03 \%\end{array}$ & $\begin{array}{c}0 \\
0 \%\end{array}$ & 30 \\
\hline Total & 445 & 330 & 225 & 1000 \\
\hline
\end{tabular}

Table 8: Comparision of various subjective and objective treatment needs.

\begin{tabular}{|c|c|c|c|c|c|c|c|}
\hline \multirow{2}{*}{$\begin{array}{l}\text { Subjective } \\
\text { treatment need }\end{array}$} & \multicolumn{6}{|c|}{ Objective treatment need } & \multirow[b]{2}{*}{ Total } \\
\hline & Filling/RCT & Extraction & Scaling & Correction & Replacement & $\begin{array}{c}\text { No. } \\
\text { treatment }\end{array}$ & \\
\hline Filling/RCT & 116 & 73 & 78 & 18 & 12 & 10 & 307 \\
\hline Extraction & 16 & 26 & 36 & 4 & 1 & 4 & 87 \\
\hline Scaling & 19 & 19 & 71 & 10 & 5 & 2 & 126 \\
\hline $\begin{array}{l}\text { Correction } \\
\text { of teeth }\end{array}$ & 20 & 4 & 18 & 50 & 0 & 2 & 94 \\
\hline Replacement & 22 & 16 & 32 & 0 & 87 & 1 & 158 \\
\hline Don't know & 32 & 48 & 127 & 6 & 14 & 1 & 228 \\
\hline Total & 225 & 186 & 362 & 88 & 119 & 20 & 1000 \\
\hline
\end{tabular}

\section{Discussion}

The professionally assessed measurements do not necessarily give the true version of the needs, but apparently, the true needs are somewhere between 'subjective' and 'objective' needs. Patient compliance, treatment response, medical and economic barriers, service availability, and the dentist's skill are factors contributing to the treatment of the individual patient.

People from all age groups visited the dental hospital. It was evident from the results that there is a negative correlation in age and dental attendance. Only $11.7 \%$ of the patients above the age of 55 years visited dental hospitals. The mean age group from of patients reporting to the dental clinics was 34 years \pm 14.06 .

Women in this study expressed more need and less satisfaction with their oral health status than men and tended to use more health care services than men. This finding is similar to the finding of a study done by Mosha et al. [11] in which they have found that dissatisfaction with their own dental status was more common in women( $60.5 \%)$ than among men $(51.7 \%)$. This may be explained by the attitudinal difference and that the barriers to seeking care may be less among women due to good educational facilities in this area. It was seen that female patients visited more dental clinics than male patients. This may suggest those female patients are more aware and more apprehensive than males. In India, around $75 \%$ of the population live in the rural area, but in this particular study rural subjects consist only 440 of the total subjects while urban constitute 580 subjects

Looking at this we can say that It may suggest that people from urban areas utilize more dental services than rural areas which may be due to various reasons like less awareness of dental problems in rural areas or difficulties of getting the services or due to barriers related to transportations. This finding is different to the finding which was reported a national survey in Tanzania which state that 12 perceived need is more common in the rural area. 
Very few illiterate people visited the dental hospital. With this finding, we can say that as the education level increases the awareness towards dental diseases increases resulting in more utilization of dental services.

The majority of the patient had the complaint about the decayed teeth, similar finding are reported by Ekanayake et al. [9]. They found that $30 \%$ reported for the treatment of decayed teeth and $23 \%$ reported the complaint of pain.

This is in contrast to the finding of previous studies done by Razak et al. [13], Van Palenstein et al. [14], Matee et al. [15] where it has been reported that toothache. It could be concluded that patients have presented themselves for care relatively earlier before acute symptoms such as pain developed. A possible explanation for this positive change may be that the knowledge and awareness about oral health and its effect on general well-being has increased in the general population over the past few years.

The most common reason for attending the dental hospital among the age group 55-64 years and >65 years was missing teeth. This finding is different from the finding of the study done by Saman Warnakulasuriya [5] the most common complaint was the mobility of teeth as compared to missing teeth.

The subject's subjective treatment needs were assessed and it was found that most sought subjective treatment need was filling. This may be because people are getting aware of dental caries which is the most common dental disease in India. Now a day people want to save their teeth at any cost because better education led to people understand the importance of teeth. $22.8 \%$ of the patients didn't know about the treatment options for them.

It is evident from the results that a major portion of the complaint of irregular teeth was in the age group 15-24 years. This can be explained based on the fact that young people are more concerned about their appearance than older age groups. They are influenced by their peer group.

This finding of the present study is in agreement with the finding of a study done by Tervonen et al. [16] which states that the result concerning the needs for caries and periodontal disease concerns to a greater extent younger than elderly subjects, whereas a reverse situation prevails concerning the prosthetic treatment need.

Very few patients came for the regular checkup (4.7\%). Most of them were in the age group of 15-24 years, which indicates good awareness in young people.

A major portion of the sample was unaware of the treatment. The main factor responsible for this is low awareness among people about dental health. The appropriate strategy needs to be developed to increase awareness in the community.

When the sample was assessed for their objective treatment needs, the most common need was found to be periodontal treatment (36.2\% ) followed by filling (22.5\%). A similar finding is noted in Sri Lanka [5] and Tanzania [9] where the most prevalent disease was periodontal problems. It was interesting to note that the subjective need for the periodontal problems was high in females (25.85\%) and among the males, the subject's need for the filling was high (35.3\%). It is seen in the results that overall there is an increased subjective demand for filling/RCT among males and females.
Subjects were compared according to subjective need and location. It was found that most of the patients came with the subjective need for filling follows by RCT. Out of 440, 138 (31.3\%) subjects didn't know about the treatment. which indicates low awareness among the rural population. While in the case of the urban population most of the patients came with the subjective need for the filling .very few subjects came for the extraction and 89 subjects didn't about the treatment. When the sample was divided according to age then it was observed that young patients were significantly more aware of their dental health. Females are more aware of dental health. but results could not reach a statistically significant value, which may be because of sample size variability ( $\mathrm{Cl} 95 \%$, $\mathrm{p}$-value $=0.69$ ) this is in agreement with the finding from a study done by Tervonen et al which states that no great difference in perception was observed between men and women[16].

This indicates that the urban population is significantly more aware of their dental health as compared to the rural $\left(p\right.$-value $\left.=0.000^{*}\right)$. This finding is contradictory to the finding of study 10 which states that perceived need was more common in rural populations.

A major portion of the matched needs is constituted by graduates and postgraduates. This can be explained on the basis that Education plays a major role in the development of attitude towards health and dental health. A major portion of the matched needs was constituted by the chief complaint of decayed teeth. The agreement for subjective and objective needs is high in case of a chief complaint. This can be explained on the basis that decayed teeth which is a very common dental disease, and the most common treatment is filling. Generally, people are aware of the treatment option of filling. The agreement between subjective and the objective treatment need for pain found only in $18.4 \%$ of the subjects of in case of matched need pain constitute only $6.74 \%$ of total matched needs. This may be because as pain it is difficult for the patients to recognize the underlying etiology of pain.

The present results indicating a low awareness of periodontal disorder agree with the earlier investigation $[17,18]$. It is an obligation of a dentist not only to provide care for the presenting complaint of the patients. But also to make them aware of, and provide treatment for, any other condition that is diagnosed during a routine dental examination. This has become necessary as it has been shown that patients are unable to assess their dental treatment needs accurately. Assessment of normative needs in the patients demanding dental care at an institution is there for important as such data could be used for estimating resources and manpower required to meet the additional workload. This is especially necessary for an institution like Dental Hospital where the concept in the treatment is 'total patient care as opposed to treating the complaint only.

Patient satisfaction can contribute to a lot of ineffective treatment. It also increases awareness among the people about dental health. So when planning comprehensive treatment for the patient, the patient view for the treatment should be taken into account. A realistic assessment of treatment needs should also include the self-perceived need of the patients, what treatment the patient will benefit from most. Layman's assessment of his $\mathrm{n} /$ her dental needs is influenced not only by 
inconvenience caused by dental disease or tooth loss but also by social and cultural factors. As for the methods used here, subjective treatment needs are measured directly by asking from the patients. Raising the level of perceived need reflects the improvement of people's awareness and knowledge of their dental disorder, and is likely to increase the demand for dental services.

\section{Conclusion}

A realistic assessment of treatment needs requires information not only about normative but also about perceived needs. It can be a useful tool in planning and monitoring health services and health promotion interventions. This study indicates low awareness among the population .there was a large discrepancy between subjective and objective treatment needs. Subjects who were Young, females, subjects with higher education, and from urban areas had a better match between their subjective and objective treatment needs as compared to subjects who were old, males, with low education status and belonging to rural areas. The utilization of dental services should therefore be improved not only by providing better dental facilities but to a greater extent by increasing people's awareness and knowledge of their dental disorders and by attempting to change their attitudes and behavior in relation to oral health care.

\section{References}

1. Burgersdijk RC, Truin GT, Kalsbeek H, et al. (1991) Objective and subjective need for cosmetic dentistry in Adult population. Community Dent Oral Epidemiol 19(2): pp. 61-63.

2. Oral health surveys-basic methods. 4th Edition (1997) World health organization, Geneva.

3. Ruse J, Heloe LA (1978) Oral condition and need for dental treatment in an elderly in northern Norway. Community Dent Oral Epidemiol 6(1): pp. 6-11.

4. Spencer AJ (1980) The estimation of the need for dental care. J Public Health Dent 40(4): pp. 311-27.

5. Warnakulasuriya S (1985) Demand for dental care in Sri Lanka. Community Dent Oral Epidemiol 13(2): pp. 68-69.

6. Gugushe TS (2000) Estimation of dental caries treatment needs--a review of the literature. SADJ 55(12): pp. 688-693.
7. Lahti S, Tuutti H, Honkal E (1989) Comparison of numbers of remaining teeth from questionnaires and clinical examination. Proc Finn Dent Soc 85(3): pp. 217-223.

8. Ogginik AO (2004) Dental care needs and demands in patients attending the dental hospital of the Obafemi Awolowo University Teaching Hospital's Complex Ile-Ife, Nigeria. Niger J Med 13(4): pp. 339-44.

9. Ekanayake L, Weerasekare C, Ekanayake N (2001) Needs and demands for dental care in patients attending the University Dental Hospital in Sri Lanka. Int Dent J 51(2): pp 67-72.

10. Ankkuriniemi O, Ainamo J (1997) Dental health and dental treatment needs among recruits of the Finnish Defence Forces 1919-91. Acta Odontol Scand 55(3): pp. 192-197.

11. Mosha HJ, Scheutz F (1993) Perceived need and oral health services among adolescents and adults in Tanzania. Community Dent Oral Epidemiol 21(3): pp. 129-132.

12. Locker D (1989) An introduction to Behavioural Science and Dentistry. 1st edition London: Tavistock/Routledge.

13. Razak A, Jaafar N (1987) Dental needs and demands and service utilization in a selected Malaysian urban population. Community Dent Oral Epidemiol 15(4): pp. 188-191.

14. Van Palenstein Helderman WH, Narthoo ZA (1990) Dental treatment needs demand among patients in Tanzania. Community Dent Oral Epidemiol 18(2): pp. 85-87.

15. Matee M, Nguvumali H, Embariti B, et al. (1999) HIV infection, Denta treatment demands and needs among patients seeking dental services at the Muhimbili medical center in Daves Salaam Tanzania. Int Dent J 49(3): pp. 153-158.

16. Tervonen T, Knuuttila M (1988) Awareness of dental disorders and the discrepancy between Objective and subjective dental treatment needs. Community Dent Oral Epidemiol 16(6): pp. 345-348.

17. Helöe LA (1972) Comparison of dental health data obtained from questionnaires, interviews and clinical examination. Scand J Dent Res 80(6): pp. 495-499.

18. Flew A (1977) Wants or needs choices or commands? In: Fitzgerald R, editor. Human needs and politics. London, Pergamon Press: pp. 213-228. 